\title{
Cation-Exchange Separation of Group V Elements: Model Experiments on Isolation and Chemical Identification of $\mathrm{Db}$
}

\author{
E. E. Tereshatov ${ }^{a}$, H. Bruchertseifer ${ }^{b}$, G. A. Bozhikov ${ }^{a}$, N. V. Aksenov ${ }^{a}$, \\ G. Ya. Starodub ${ }^{a}$, G. K. Vostokin ${ }^{a}$, A. G. Belov ${ }^{a}$, S. V. Shishkin ${ }^{a}$, S. N. Dmitriev ${ }^{a}$, \\ H. W. Gäggeler ${ }^{b}$, R. Eichler ${ }^{b}$, and D. Schumann ${ }^{b}$ \\ a Flerov Laboratory of Nuclear Reactions, Joint Institute for Nuclear Research, Dubna, \\ Moscow oblast, Russia \\ ${ }^{b}$ Paul Scherrer Institute, Villigen CH-5232, Switzerland
}

Received April 5, 2007

\begin{abstract}
A cation-exchange procedure was developed for separating $\mathrm{Nb}$ from $\mathrm{Ta}, \mathrm{Pa}$ from $\mathrm{Ta}$, and $\mathrm{Nb}$, $\mathrm{Pa}$, and $\mathrm{Ta}$ from $\mathrm{Zr}, \mathrm{Hf}$, and lanthanides in dilute $\mathrm{HCl} / \mathrm{HF}$ solutions. The stability of the fluoride complexes of Group IV and V elements decreases in the following order: $\mathrm{Nb} \approx \mathrm{Pa}>\mathrm{Zr}>\mathrm{Hf}>\mathrm{Ta}$. This procedure can be used in experiments on synthesis of superheavy nuclei for isolation of $\mathrm{Db}$ from the reaction products and for its chemical identification.

PACS numbers: $82.30 . \mathrm{Hk}$

DOI: $10.1134 / \mathrm{S} 1066362208030132$
\end{abstract}

Chemical identification and study of chemical properties of transactinide elements (TAEs) received recently a special attention. Relatively long life of the new radionuclides produced by reactions with ${ }^{48} \mathrm{Ca}$ and of their decay products open the possibilities for not only on-line (directly in heavy ion beams during continuous isolation of the reaction products) but also off-line (relatively prolonged irradiation of targets with subsequent isolation of the radionuclides) experiments. The first such experiment on chemical identification of $\mathrm{Db}$, the final decay product of element 115, was performed in 2004 in FLNR $[1,2]$.

The isotope of element 115 with an atomic weight of 288 was synthesized for the first time by the nuclear reaction ${ }^{48} \mathrm{Ca}+{ }^{243} \mathrm{Am} \rightarrow{ }^{288} 115+3$ n using a gas-filled separator of the reaction products [3]. The nuclide underwent five successive $\alpha$-decays to form ${ }^{268} \mathrm{Db}$ which decayed by spontaneous fission:

$$
\begin{gathered}
{ }^{243} \mathrm{Am}+{ }^{48} \mathrm{Ca} \stackrel{3 n}{\longrightarrow}{ }^{288} 115 \stackrel{\alpha_{1}, 10.46 \mathrm{MeV}}{125 \mathrm{~ms}}{ }^{284} 113 \\
\stackrel{\alpha_{2}, 10.00 \mathrm{MeV}}{0.69 \mathrm{~s}}{ }^{280} \mathrm{Rg} \frac{\alpha_{3}, 9.75 \mathrm{MeV}}{5.2 \mathrm{~s}}{ }^{276} \mathrm{Mt} \frac{\alpha_{4}, 9.71 \mathrm{MeV}}{1.03 \mathrm{~s}}{ }^{272} \mathrm{Bh} \\
\stackrel{\alpha_{5}, 9.02 \mathrm{MeV}}{14.14 \mathrm{~s}}{ }^{268} \mathrm{Db} \stackrel{\mathrm{SF}, 205 \mathrm{MeV}}{16 \mathrm{~h}} \text { fission products. }
\end{gathered}
$$

The total time of $5 \alpha$-decays is approximately $20 \mathrm{~s}$. The half-life of ${ }^{268} \mathrm{Db}$ estimated from the three observed events [3] is $16_{-6}^{+19} \mathrm{~h}$.

Fifteen events of spontaneous fission of ${ }^{268} \mathrm{Db}$ were detected in the course of the chemical experiment. The ${ }^{268} \mathrm{Db}$ half-life $\left(T_{1 / 2}=29 \mathrm{~h}\right)$ was refined, and the energy of the fission products and the number of neutrons emitted during fission were determined from the time distribution of the events [4]. The results of the "chemical" experiment proved independently formation of elements 115 and 113 by the reaction ${ }^{48} \mathrm{Ca}+{ }^{243} \mathrm{Am}$.

The off-line experiment is of interest not only for chemical identification but also for study of chemical properties of $\mathrm{Db}$. For this purpose, it is appropriate to use for producing the long-lived isotope ${ }^{268} \mathrm{Db}$ the procedure similar to that in [1]. More selective procedures that would allow not only isolation of Group $\mathrm{V}$ elements but also their separation (a more complex problem) should be used in the next steps. The aim of this study was to develop a cation-exchange procedure for isolating and separating Group V elements.

This procedure was developed taking into account the results of the on-line experiments on the study of chemical properties of dubnium.

Extraction of $\mathrm{Nb}, \mathrm{Ta}, \mathrm{Pa}$, and $\mathrm{Db}$ from $\mathrm{HF}, \mathrm{HCl}$, and $\mathrm{HBr}$ solutions with aliphatic amines was studied 
in [5-9]. The stability of Group V metal halide complexes was shown to decrease in the following order: $\mathrm{F}^{-}>\mathrm{Cl}^{-}>\mathrm{Br}^{-}$. However, the results of these studies do not provide sufficient information to compare unambiguously the stability of halide complexes of $\mathrm{Db}$ with that of the complexes of its homologs $\mathrm{Nb}$ and $\mathrm{Ta}$ and pseudohomolog $\mathrm{Pa}$.

Pershina $[10,11]$ studied the hydrolysis and complexation of Group V elements ( $\mathrm{Nb}$, Ta, and $\mathrm{Pa}$ ) in hydrogen halide solutions. Based on the results of quantum chemical calculations, she suggested that hydrolysis decreased in the order $\mathrm{Ta}>\mathrm{Db}>\mathrm{Nb}>\mathrm{Pa}$ and the competing complexation with halide anions decreased in the reverse order: $\mathrm{Pa}>\mathrm{Nb}>\mathrm{Db}>\mathrm{Ta}$.

Sorption of Group IV and V elements on an anion exchanger from fluoride solutions was studied previously [12, 13]. Caletka and Krivan [12] showed that, in a wide range of HF concentrations, the sorption of these elements decreased in the order $\mathrm{Ta}>$ $\mathrm{Hf} \approx \mathrm{Zr}>\mathrm{Pa}$. At the HF concentration lower than $0.3 \mathrm{M}$, the sorption decreased in the order $\mathrm{Ta}>$ $\mathrm{Hf} \approx \mathrm{Zr}>\mathrm{Pa}>\mathrm{Nb}$ [13].

Previously we studied complexation of Group IV and $\mathrm{V}$ elements in aqueous solutions with different $\mathrm{HF}$ concentrations. $\mathrm{Zr}$ complexes formed in dilute HF solutions are sorbed on the cation-exchange resin, and the negatively charged $\mathrm{Nb}$ complexes remain in the solution. We showed that anionic $\mathrm{Nb}$ fluoride complexes were formed in $0.1 \mathrm{M} \mathrm{HCl}$ solutions containing $10^{-3}-10^{-5} \mathrm{M}$ HF. At $[\mathrm{HF}]<5 \times$ $10^{-4} \mathrm{M}$, neutral and cationic $\mathrm{Nb}$ species appear.

Thus, the strongest difference in the behavior of Group $\mathrm{V}$ and IV elements should be observed in dilute $\mathrm{HCl} / \mathrm{HF}$ solutions.

\section{EXPERIMENTAL}

Carrier-free tracers were produced by $(\alpha, x n)$ and $(n, \gamma)$ reactions and by the fission reaction $(p ; x n, y p$, $f$ ) on the U-200 cyclotron, MT-25 microtron (FLNR, JINR), and $\mathrm{F}$ synchrocyclotron (Laboratory of $\mathrm{Nu}-$ clear Problems, JINR), respectively. The half-lives and production reactions of the isotopes used in this study are given below.

\begin{tabular}{rll} 
Isotope & \multicolumn{1}{c}{ Production reaction } & \multicolumn{1}{c}{ Half-life } \\
${ }^{233} \mathrm{~Pa}$ & ${ }^{232} \mathrm{Th}(n, \gamma)^{233} \mathrm{Th} \rightarrow{ }^{233} \mathrm{~Pa}$ & 27.0 days \\
${ }^{92 m} \mathrm{Nb}$ & ${ }^{n a t} \mathrm{Y}(\alpha, x n){ }^{92 m} \mathrm{Nb}$ & 10.15 days \\
${ }^{177} \mathrm{Ta}$ & ${ }^{n a t} \mathrm{Lu}(\alpha, x n){ }^{177} \mathrm{Ta}$ & $56.6 \mathrm{~h}$ \\
${ }^{88} \mathrm{Zr}$ & ${ }^{n a t} \mathrm{Sr}(\alpha, x n)^{88} \mathrm{Zr}$ & 83.4 days \\
${ }^{175} \mathrm{Hf}$ & ${ }^{n a t} \mathrm{Yb}(\alpha, x n){ }^{175} \mathrm{Hf}$ & 70 days \\
${ }^{87 m} \mathrm{Sr}$ & ${ }^{n a t} \mathrm{Rb}(\alpha, x n)^{87} \mathrm{Y} \rightarrow{ }^{87 m} \mathrm{Sr}$ & $2.81 \mathrm{~h}$ \\
${ }^{173} \mathrm{Lu}$ & ${ }^{n a t} \mathrm{Ta}(p ; x n, y p, f)^{173} \mathrm{Lu}$ & 1.37 years
\end{tabular}

RADIOCHEMISTRY Vol. 50 No. 32008
Chemical isolation of $\mathrm{Pa}, \mathrm{Nb}$, and $\mathrm{Ta}$ was performed as follows.

${ }^{233} \mathrm{~Pa}$ production. A set of thorium foils of different thicknesses and total weight of $0.9 \mathrm{~g}$ was placed in a cylindrical plastic container and was irradiated with thermal neutrons using a U-Be converter of the MT-25 microtron [neutron flux $10^{8} n \mathrm{~cm}^{-2} \mathrm{~s}^{-1}$ ] for $10 \mathrm{~h}$. After irradiation completion, the foils were allowed to stand for 3 days and were then dissolved in $11.3 \mathrm{M} \mathrm{HCl}(10 \mathrm{ml})$ containing $2 \mathrm{M} \mathrm{HF}$ (1-2 drops) to facilitate the dissolution. The resulting solution was passed through an $8 \times 40 \mathrm{~mm}$ anion-exchange column packed with AG $1 \times 8$ resin (10-200 mesh). Then the column was washed with $8 \mathrm{M} \mathrm{HCl}(9 \mathrm{ml})$. $\mathrm{Pa}$ was eluted with $2 \mathrm{M} \mathrm{HCl}(6 \mathrm{ml})$. Approximately $95 \%$ of $\mathrm{Pa}$ was isolated.

${ }^{92 m_{\mathrm{Nb}}}\left({ }^{177} \mathrm{Ta}\right)$ production. Yttrium (lutetium) nitrate applied to an aluminum support was calcined. The resulting rare-earth oxide $\mathrm{Y}_{2} \mathrm{O}_{3}\left(\mathrm{Lu}_{2} \mathrm{O}_{3}\right)(100-$ $130 \mathrm{mg} / 10 \mathrm{~cm}^{2}$ ) was irradiated on the U-200 accelerator with $\alpha$-particles (32-33 MeV) for $10 \mathrm{~h}(6 \mathrm{~h})$ at an average current of $10 \mu \mathrm{A}(7 \mu \mathrm{A})$. After irradiation completion, the sample was allowed to stand for $100 \mathrm{~h}$. Then the oxide layer was dissolved in concentrated $\mathrm{HNO}_{3}(10 \mathrm{ml})$. The solution was evaporated to dryness, and the dry residue was dissolved in $\mathrm{HNO}_{3} . \mathrm{YF}_{3}\left(\mathrm{LuF}_{3}\right)$ was precipitated by the addition of $\mathrm{HF}$ to the composition of $0.5 \mathrm{M} \mathrm{HNO}_{3}+1-$ $1.5 \mathrm{M} \mathrm{HF}$. Then the mixture was centrifuged for $5 \mathrm{~min}(4000 \mathrm{rpm})$, and the solution was decanted and evaporated to dryness. The dry residue was dissolved in $3 \mathrm{M} \mathrm{HF}(100 \mu \mathrm{l})$. The resulting solution was passed through an anion-exchange column $(2 \times 50 \mathrm{~mm})$ packed with Dowex $1 \times 8$ resin $(200-$ 400 mesh). $\mathrm{Nb}$ (Ta) was eluted with $0.5 \mathrm{M} \mathrm{HNO}_{3}+$ $1.5 \% \quad \mathrm{H}_{2} \mathrm{O}_{2}$.

Isolation of $\mathrm{Lu}, \mathrm{Zr}, \mathrm{Hf}$, and $\mathrm{Sr}$ was described in detail in our previous papers [2, 16, 17].

The solutions of the examined radioisotopes were mixed, and the carrier of the corresponding isotope $(1 \mu \mathrm{g})$ and $\mathrm{La}(1 \mathrm{mg})$ in the form of $\mathrm{La}\left(\mathrm{NO}_{3}\right)_{3}$ were added. The lanthanum amount was determined by the procedure for separating reaction products from the target material, described in [1]. The solution was evaporated with a few drops of aqua-regia and then was evaporated to dryness.

The dry residue was dissolved in $0.2 \mathrm{M} \mathrm{HCl}$ $(0.5 \mathrm{ml})$. The resulting solution was applied to a $6 \times 30$-mm column containing Dowex $50 \times 8$ resin (100-200 mesh). The elements were separated by washing of the column with mineral acid solutions of 


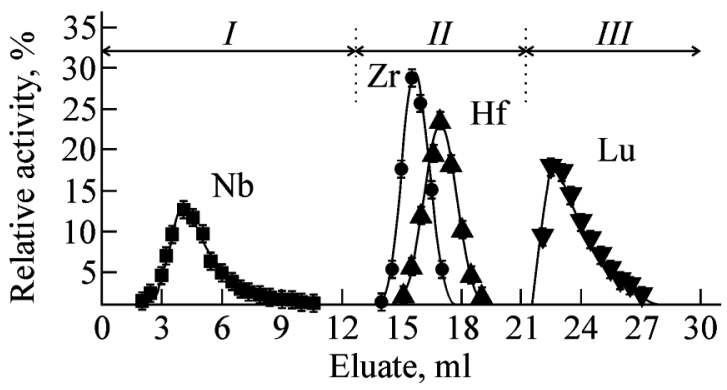

Fig. 1. Cation-exchange separation of $\mathrm{Nb}, \mathrm{Zr}$, $\mathrm{Hf}$, Ta, and $\mathrm{Lu}$ (Dowex $50 \times 8,100-200 \mathrm{mesh}, 6 \times 30 \mathrm{~mm}$ ). Eluent: (I) $0.2 \mathrm{M} \mathrm{HCl}+5 \times 10^{-4} \mathrm{M} \mathrm{HF}$, (II) $0.2 \mathrm{M} \mathrm{HCl}+2 \times$ $10^{-3} \mathrm{M} \mathrm{HF}$, and (III) $6 \mathrm{M} \mathrm{HCl}$.

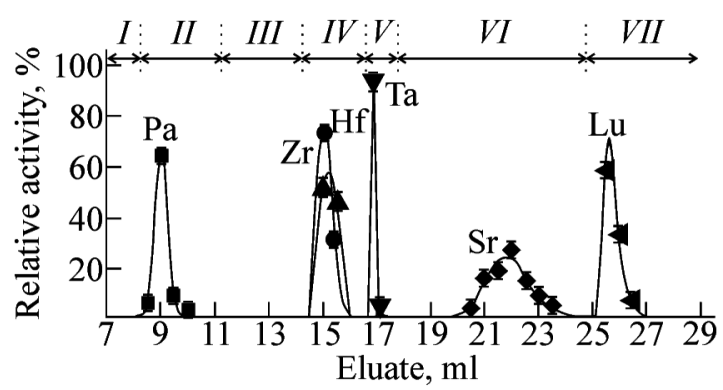

Fig. 2. Cation-exchange separation of $\mathrm{Pa}, \mathrm{Zr}, \mathrm{Hf}, \mathrm{Sr}$, and $\mathrm{Lu}$ (Dowex $50 \times 8,100-20 \mathrm{mesh}, 6 \times 30 \mathrm{~mm}$ ). Eluent, M: (I) $0.2 \mathrm{M} \mathrm{HCl}+5 \times 10^{-4} \mathrm{M} \mathrm{HF},(I I) 0.2 \mathrm{M} \mathrm{HCl}+7.5 \times$ $10^{-4} \mathrm{M} \mathrm{HF},(I I I) 0.2 \mathrm{M} \mathrm{HCl}+1 \times 10^{-3} \mathrm{M} \mathrm{HF},(I V) 0.2 \mathrm{M}$ $\mathrm{HCl}+5 \times 10^{-3} \mathrm{M} \mathrm{HF},(V) 1 \mathrm{MHF},(V I) 2 \mathrm{M} \mathrm{HNO}_{3}$, and (VII) $6 \mathrm{M} \mathrm{HCl}$.

different concentrations. The element fractions were analyzed on a $\gamma$-ray spectrometer with a Ge detector (ORTEC) by the standard procedure.

The conditions of sorption of the examined elements on the cation-exchange resin $(0.2 \mathrm{M} \mathrm{HCl})$ were estimated using the Speciation software (IUPAC SC-Database/Academic Software) [18].

\section{RESULTS AND DISCUSSION}

First we studied cation-exchange separation of $\mathrm{Nb}, \mathrm{Zr}$, Hf, and Lu on Dowex $50 \times 8$ resin (Fig. 1). Niobium was eluted first, with $0.2 \mathrm{M} \mathrm{HCl}+5 \times$ $10^{-4} \mathrm{M} \mathrm{HF}$; then Group IV elements ( $\mathrm{Zr}$ and $\mathrm{Hf}$ ) were eluted with $2 \mathrm{M} \mathrm{HCl}+2 \times 10^{-3} \mathrm{M} \mathrm{HF}$; and finally $\mathrm{Lu}$ was eluted with $6 \mathrm{M} \mathrm{HCl}$. It should be noted that separation of $\mathrm{Nb}$ from $\mathrm{Zr}$ and $\mathrm{Hf}$ confirms the correct choice of the initial separation conditions. The behavior of the elements being separated supports the results of the on-line separation of $\mathrm{Nb}$ and $\mathrm{Zr}$ on a SISAK unit [14]. It should be noted that, since the $\mathrm{Zr} / \mathrm{Hf}$ separation factor $\alpha_{\mathrm{Zr} / \mathrm{Hf}}$ is about 1.1, separation of these elements under similar conditions is possible. Group IV and V elements were also separated from actinides simulated by $\mathrm{Lu}$.

The aim of next step was to study the behavior of $\mathrm{Pa}$ (Db pseudohomolog) and $\mathrm{Ta}$ under these conditions. In these experiments, ${ }^{87 m} \mathrm{Sr}$, a chemical analog of No, was introduced into the mixture to be separated. No can be formed by the following reaction:

$$
\mathrm{Db} \stackrel{\mathrm{EC}}{\longrightarrow} \mathrm{Rf} \stackrel{\alpha}{\longrightarrow} \text { No. }
$$

The separation results are shown in Fig. 2. $\mathrm{Pa}$ was eluted with $0.2 \mathrm{M} \mathrm{HCl}+7.5 \times 10^{-4} \mathrm{M} \mathrm{HF}$. Then, Group IV elements ( $\mathrm{Zr}, \mathrm{Hf})$ were eluted with $0.2 \mathrm{M} \mathrm{HCl}+5 \times 10^{-3} \mathrm{M} \mathrm{HF} ; \mathrm{Ta}, \mathrm{Sr}$, and $\mathrm{Lu}$ were eluted with $1 \mathrm{M} \mathrm{HF}, 2 \mathrm{M} \mathrm{HNO}_{3}$, and $6 \mathrm{H} \mathrm{HCl}$, respectively.

Since Ta is eluted after Group IV elements, the location of the Ta band on the chromatogram is of interest. Presumably, the stability constant of the Ta fluoride complex is significantly lower than that of the related complexes of the other examined elements. Our first experimental results showed that the elution peaks of $\mathrm{Pa}$ and $\mathrm{Nb}$ are close.

In addition, as seen from the chromatogram, in the case of No formation by the above scheme, this procedure allows complete separation of Group IV and $\mathrm{V}$ elements from $\mathrm{Sr}$ (No analog) and $\mathrm{Lu}$ (an analog of trivalent actinides). Thus, the decontamination factor of the examined elements from actinides is as high as $\sim 10^{4}$.

Thus, a cation-exchange procedure was developed for the separation of $\mathrm{Nb}$ from $\mathrm{Ta}, \mathrm{Pa}$ from $\mathrm{Ta}$, and also of $\mathrm{Nb}$, Ta, and $\mathrm{Pa}$ from $\mathrm{Zr}$, Hf, and lanthanides in dilute $\mathrm{HCl} / \mathrm{HF}$ solutions. The behavior of the $\mathrm{Pa}+\mathrm{Nb}$ system under these conditions requires additional study.

Our results show that the stability of the fluoride complexes of Group IV and $\mathrm{V}$ elements decreases in the following order: $\mathrm{Nb} \approx \mathrm{Pa}>\mathrm{Zr}>\mathrm{Hf}>\mathrm{Ta}$. The behavior of these elements in the examined solutions is consistent with results of the previous studies and theoretical calculations.

Thus, the developed procedure allows selective separation of Group V elements from their analogs $\mathrm{Rf}(\mathrm{Zr}, \mathrm{Hf})$ and from heavy actinides $(\mathrm{Cm}, \mathrm{Cf})$ and nuclear-physical analysis of several fractions obtained in the course of the study of chemical properties of $\mathrm{Db}$ and its identification. 


\section{ACKNOWLEDGMENTS}

The authors are grateful to T.V. Shishkina for assistance in radiochemical separation and to Ts.N. Piperov for theoretical calculations.

This study was financially supported by the Russian Foundation for Basic Research (project nos. 0403-32047 and 07-03-00430).

\section{REFERENCES}

1. Dmitriev, S.N. Oganessian, Yu.Ts., Utyonkov, V.K., et al., Mendeleev Commun., 2005, vol. 15, no. 1, pp. $1-4$.

2. Schumann, D., Bruchertseifer, H., Eichler, R., et al., Radiochim. Acta, 2005, vol. 93, pp. 727-732.

3. Oganessian, Yu.Ts., Utyonkov, V.K., Lobanov, Yu.V., et al., Phys. Rev. C, 2004, vol. 69, $021601(\mathrm{R})$.

4. Oganessian, Yu.Ts., Utyonkov, V.K., Dmitriev, S.N., et al., Phys. Rev. C, 2005, vol. 72, 034611.

5. Kratz, J.V., Zimmermann, H.P., Scherer, U.W., et al., Radiochim. Acta, 1989, vol. 48, pp. 121-133.

6. Zimmermann, H.P., Gober, M.K., Kratz, J.V., et al., Radiochim. Acta, 1993, vol. 60, pp. 11-16.

7. Gober, M.K., Kratz, J.V., Zimmermann, H.P., et al., Radiochim. Acta, 1992, vol. 57, pp. 77-84.
8. Paulus, W., Kratz, J.V., Strub, E., et al., J. Alloys Comp., 1998, vol. 271-273, pp. 292-295.

9. Paulus, W., Kratz, J.V., Strub, E., et al., Radiochim. Acta, 1999, vol. 84, pp. 69-77.

10. Pershina, V., Radiochim. Acta, 1998, vol. 80, pp. 75 84.

11. Pershina, V. and Bastug, T., Radiochim. Acta, 1999, vol. 84, pp. 79-84.

12. Caletka, R. and Krivan, V., J. Radioanal. Nucl. Chem., 1990, vol. 142, no. 2, pp. 359-371.

13. Monroy-Guzman, F., Trubert, D., Brillard, L., et al., J. Radioanal. Nucl. Chem., 1996, vol. 208, no. 2, pp. 461-466.

14. Bruchertseifer, H., Heller, W., Haberberger, F., et al., GSI Scientific Report 1990, Darmstadt: GSI, 1991, no. 91-1, p. 265.

15. Bruchertseifer, H., Heller, W., Binder, R., et al., ZFI-Mitteilungen, Leipzig: ZFI, 1991, no. 166, pp. 53-56.

16. Bozhikov, G.A., Priemyshev, A.N., Bontchev, G.D., et al., Heavy Ion Physics: JINR FLNR, Scientific Report 1999-2000, Dubna, 2001, p. 127.

17. Suess R., Bruchertseifer, H., Heller, W., et al., ZFIReport, Leipzig: ZFI, 1989, no. 81.

18. Pettit, L.D. and Powell, K.J., Speciation Program, The IUPAC Stability Constants Database (IUPAC and Academic Software), http:www.acadsoft.co.uk/, 1993-2001. 